\title{
A Specific, Robust, and Automated Method for Routine At-Line Monitoring of the Concentration of Cellulases in Genetically Modified Sugarcane Plants
}

\author{
Ruchi Gupta • Sara J. Baldock • Peter R. Fielden • \\ Bruce D. Grieve
}

Received: 1 April 2010 / Accepted: 9 August 2010 /

Published online: 8 December 2010

(C) Springer Science+Business Media, LLC 2010

\begin{abstract}
Bagasse is one of the waste crop materials highlighted as commercially viable for cellulosic bio-ethanol production via enzymatic conversion to release fermentable sugars. Genetically modified sugarcane expressing cellobiohydrolases $(\mathrm{CBH})$, endoglucanase (EG), and $\beta$-glucosidases $(\mathrm{BG})$ provide a more cost-effective route to cellulose breakdown compared to culturing these enzymes in microbial tanks. Hence, process monitoring of the concentration profile of these key cellulases in incoming batches of sugarcane is required for fiscal measures and bio-ethanol process control. The existing methods due to their nonspecificity, requirement of trained analysts, low sample throughput, and low amenability to automation are unsuitable for this purpose. Therefore, this paper explores a membrane-based sample preparation method coupled to capillary zone electrophoresis (CZE) to quantify these enzymes. The maximum enzyme extraction efficiency was obtained by using a polyethersulfone membrane with molecular cut-off of $10 \mathrm{kDa}$. The use of $15 \mathrm{mM}, \mathrm{pH} 7.75$, phosphate buffer resulted in CZE separation and quantification of $\mathrm{CBH}, \mathrm{EG}$, and $\mathrm{BG}$ within $10 \mathrm{~min}$. Migration time reproducibility was between $0.56 \%$ and $0.7 \%$ and hence, suitable for use with automatic peak detection software. Therefore, the developed CZE method is suitable for atline analysis of $\mathrm{BG}, \mathrm{CBH}$, and EG in every batch of harvested sugarcane.
\end{abstract}

Keywords Bio-fuel · Sugarcane $\cdot$ Enzyme expression · Process monitoring · Capillary zone electrophoresis

R. Gupta $(\triangle) \cdot$ B. D. Grieve

School of Electrical and Electronics Engineering, The University of Manchester,

Sackville Street Building, Manchester M13 9PL, UK

e-mail: ruchi.gupta@postgrad.manchester.ac.uk

B. D. Grieve

e-mail: bruce.grieve@manchester.ac.uk

S. J. Baldock $\cdot$ P. R. Fielden

School of Chemical Engineering and Analytical Science, Manchester Interdisciplinary Biocentre, The University of Manchester, 131 Princess Street, Manchester M1 7DN, UK

S. J. Baldock

e-mail: sara.baldock@manchester.ac.uk

P. R. Fielden

e-mail: peter.fielden@manchester.ac.uk 


\section{Introduction}

Global energy consumption continues to increase while fossil-fuel reserves are diminishing. To avert a looming energy crisis, the development of renewable energy sources is becoming a priority. In particular, bio-ethanol is considered to have a potential to decrease our dependence on petroleum-derived transportation fuels [1]. While the use of crops for bio-ethanol production has been controversial, the production of bio-ethanol from crop wastes (such as bagasse) does not create pressure on existing food and land resources. In comparison to other crop wastes, the use of sugarcane bagasse is particularly attractive with the most positive energy balance in the near term [2]. Furthermore, dry bagasse consists of $40-50 \%$ cellulose, thereby presenting a lucrative commercial opportunity for bio-ethanol production [3]. It is estimated that just $50 \%$ of the current Australian sugarcane bagasse crop could produce approximately 1.2 billion liters of bio-ethanol per annum [4] which is equivalent to about $2 \%$ of the country's gasoline consumption in 2006 [5]. However, the hydrolysis of cellulose in pre-treated bagasse to release fermentable sugars requires a synergistic action of cellobiohydrolase $(\mathrm{CBH})$, endo- $\beta$-glucanse (EG), and $\beta$-glucosidase (BG). The production of these enzymes in industrial reactors is expensive (approximately USD $0.10 / 1$ of ethanol) and is the key barrier to economic production of ethanol from bagasse. Genetically modified (GM) plants expressing multiple cellulases have the potential to provide a more cost-effective source of cellulosic enzymes [6].

Currently, mills screen each incoming batch of sugarcane and make payments to growers based on sucrose content of their sugarcane. But an additional parameter, i.e., quantification of $\mathrm{BG}, \mathrm{CBH}$, and $\mathrm{EG}$ has to be incorporated to the payment scheme of GM sugarcane growers. This is because the exact concentration of enzymes is likely to be dependent upon environmental factors, cane variety, cultivation, and harvesting conditions despite the incorporation of "gene switches" [7]. In addition, the hydrolysis efficiency of a particular enzyme is dependent on the concentration of other enzymes. Therefore, it is imperative to obtain a concentration profile of individual enzymes to assess a mixture's cellulosic conversion efficiency. The information obtained could also be used to provide a feedback to farmers to assist with their agronomic practices, i.e., their cultivation and harvesting conditions to maximize the expression of enzymes in planted GM cane. Furthermore, the data on the concentration of expressed enzymes could be used to determine the amount of processing or means of processing required before they could be added to the hydrolysis tank. While online analysis has an ability to enable near real-time monitoring, it presents more technical challenges such as blockages due to solid particles (such as sand, fiber particles, and so on) and surface adsorption of organic matter (e.g., sucrose, glucose, fructose, salts, proteins, starch, dextran, waxes, and phosphatides) [8]. Therefore, at-line analysis is a simple, low cost option for measuring the concentration of $\mathrm{BG}, \mathrm{CBH}$, and EG in every incoming batch of sugarcane.

Today the total protein concentration is measured by using the bicinchoninic acid (BCA) protein assay. But sensitivity of reagents used in conventional BCA assays towards reducing sugars results in inaccurate estimation of enzymes in the juice [9]. In addition, BCA assay is not suitable to obtain a profile of individual enzymes in an enzyme mixture. Various enzymatic assays have been reported in the literature as a solution to this problem. The viscometric method though specific for EG [10] is time-consuming, labor intensive, and limits the number of samples that can be handled [11]. Therefore, to decrease the analysis time, synthetic substrates such as p-nitrophenyl- $\beta$-D-cellobioside and p-nitrophenyl- $\beta$-Dglucopyranoside have been used successfully for the measurement of EG and BG activities, 
respectively [12]. However, there is no standard assay to measure the activity of $\mathrm{CBH}$ in cellulase complexes [13].

A straightforward idea to quantify multiple cellulase enzymes in a mixture is to separate them before quantification. Gel electrophoresis-based separation methods such as SDSPAGE and isoelectric focusing (IEF) are difficult to automate and are subject to operator interpretation due to the visual nature of the output data. In addition, most staining dyes are unable to stain glycoproteins and have a poor linear dynamic range making quantitative analysis difficult [14]. Although IEF in capillaries (cIEF) offers higher automation capabilities, the added complexity of the mobilization process has been an obstacle in achieving reproducible cIEF separations [15]. Multi-step analysis and a long analysis time of the combined fast protein liquid chromatography and ion-exchange chromatography [16-18] for the separation of cellulases make chromatography-based techniques unsuitable for the accurate and high-throughput quantification of enzymes in numerous samples. Unlike the parabolic profile of the hydrodynamic flow in chromatography, the characteristic plug-like flow profile of a capillary zone electrophoresis (CZE) separation leads to lower peak dispersion resulting in higher separation efficiency. Therefore, CZE has a potential to separate and quantify $\mathrm{CBH}, \mathrm{EG}$, and BG in a single step. One of the major problems of using CZE for biological samples is unpredictable shifts in migration time due to the sample matrix. But migration time is crucial for compound identification especially when multiple species are present. Hence, routine analysis of biological samples by using CZE demands stringent sample preparation [19].

For the first time, this work reports a membrane-based sample preparation method for the CZE separation of cellulosic enzymes in sugarcane juice. The effect of molecular weight cut-off (MWCO) point of the membrane on the enzyme extraction efficiency has been investigated. The effect of $\mathrm{pH}$ and concentration of buffer on $\mathrm{CBH}$ and $\mathrm{EG}$ (from Trichoderma longibrachiatum) and BG (from Aspergillus niger) is studied and optimized in this study. The above-mentioned enzyme mixture meets the minimum conditions required for efficient hydrolysis of cellulose and expressing at those levels would not produce detrimental effects on plants during their growth and development at ambient temperatures as their temperature optima are between $40^{\circ} \mathrm{C}$ and $70^{\circ} \mathrm{C}$ [20]. In addition, the knowledge on the regulation mechanism of these enzymes in Trichoderma and Aspergillus could be used to control their expression in GM plants [21, 22]. The quantitative details on method validation such as reproducibility of migration times of these enzymes are also presented. Finally, the calibration plots and limit of detection of cellulosic enzymes are included. It should be noted that while cellulase enzymes have been separated by Khaled et al. [23] at $\mathrm{pH}$ 9.2, only a single research group has quantified cellulases by CZE [24-26]. However, the work conducted by Jørgensen et al. [24-26] used the enzymes from Penicillium brasilianum Batista IBT 20888 instead of Trichoderma and A. niger. In addition, no reports were made on the effect of a wider range of $\mathrm{pH}$ and concentration of the buffer on the separation of cellulases. The analysis time of the method reported in this paper is at least $40 \%$ lower than the separation time reported in the previous studies.

\section{Experimental}

\section{Materials}

All samples and electrolytes were prepared using 18.2 M $\Omega$ water (Direct-Q ${ }^{\mathrm{TM}} 5$ Ultrapure Water Systems, Millipore, Hampshire, UK). 
In order to make standard enzyme solutions for peak identification and calculation of extraction efficiency of sample preparation and to obtain calibration curves, $\mathrm{CBH}$ and EG from T. longibrachiatum and BG from A. niger in $3.2 \mathrm{M}$ ammonium sulfate and $0.02 \%$ sodium azide were bought from Megazyme (Bray, Ireland). It should be noted that BG enzyme suspension was supplied with approximately $1 \mathrm{mg} / \mathrm{ml}$ of bovine serum albumin (BSA) to alleviate stability problems due to the dilution of BG. The molecular weights of $\mathrm{BG}, \mathrm{CBH}$, and $\mathrm{EG}$ used in this work are 121, 65, and $57 \mathrm{kDa}$ [27], respectively. Since the calculated molecular weights based on amino acid sequence [28] disregard the contribution of saccharides attached to these enzymes [29], the reported molecular weights are higher than those calculated based on their amino acids sequence alone. Hence, desalting of enzymes was performed by using $10 \mathrm{kDa}$ MWCO Vivaspin ${ }^{\mathrm{TM}} 6$ polyethersulfone columns (Sartorius, Surrey, UK) according to the manufacturer's instructions. The concentration of desalted CBH, EG, and BG were measured by using (a) RC-DCTM protein assay (Bio-Rad, Hertsfordshire, UK) using BSA as a standard and (b) absorbance at $280 \mathrm{~nm}$ using NanoDrop ${ }^{\text {TM }} 2000$ (Thermo Scientific, Hampshire, UK) following the manufacturer's instructions.

Samples of fresh, raw sugarcane juice were shipped from the Queensland University of Technology, Australia in the frozen state. The sample was defrosted in a water bath at $40^{\circ} \mathrm{C}$, divided into aliquots of $\sim 1.5 \mathrm{ml}$ and stored at $-4^{\circ} \mathrm{C}$. Each aliquot was defrosted and centrifuged at $14,000 \times \mathrm{g}$ for $3 \mathrm{~min}$ (to remove solid particles such as sand) after which the supernatant was collected to perform CZE experiments.

The phosphate buffer used in this work was made by using the following chemicals: sodium phosphate monobasic (99.6\%, Sigma-Aldrich, Gillingham, UK), and disodium hydrogen orthophosphate dodecahydrate (99.85\%, Fisher Scientific, Loughborough, UK).

\section{Sample Preparation}

Purification of enzymes in sugarcane juice was performed by using columns with 30 and $10 \mathrm{kDa}$ MWCO polyethersulfone (Vivaspin ${ }^{\mathrm{TM}} 500$, Sartorius) membranes. Basically, $0.1 \mathrm{ml}$ of juice containing $\mathrm{CBH}, \mathrm{EG}$, and $\mathrm{BG}$ was added to the column. The column was then centrifuged at $14,000 \times \mathrm{g}$ for $20 \mathrm{~min}$ reducing the volume of the concentrate to $\sim 50 \mu \mathrm{l}$. The column was topped up with $50 \mu \mathrm{l}$ of water and centrifuged (14,000 $\times \mathrm{g}$ for $20 \mathrm{~min})$ to reduce the volume to $\sim 20 \mu \mathrm{l}$. Finally, $80 \mu \mathrm{l}$ of water was added to the filter. The sample was collected by using a pipette.

A stock solution of volume $0.2 \mathrm{ml}$ was prepared by adding 2,2 , and $7 \mu$, respectively, of standard $\mathrm{CBH}, \mathrm{EG}$, and (BG+BSA) enzyme solutions to the sugarcane juice. The stock solution was divided into two aliquots of $0.1 \mathrm{ml}$ each. Both of these aliquots underwent filtration using different MWCO PES filter membranes. The corrected peaks areas of BG, $\mathrm{CBH}$, and EG were used to estimate the concentration of these enzymes after sample preparation and to calculate the extraction efficiency of the method.

\section{Capillary Electrophoresis}

A P/ACETM MDQ (Beckman Coulter, High Wycombe, UK) was used for the CZE separations presented in this paper. A neutral capillary of $50 \mu \mathrm{m}$ I.D. and total length of $63 \mathrm{~cm}$ with an online detection window at $11 \mathrm{~cm}$ from the end was housed in a cartridge which allowed liquid cooling to maintain a constant capillary temperature of $25^{\circ} \mathrm{C}$. A neutral capillary was chosen because its walls are coated with polyacrylamide which decreases electroosmotic flow (EOF) and reduces wall interaction with proteins and basic 
samples. The capillary was prepared by sequentially flushing with $\mathrm{H}_{2} \mathrm{O}, 0.1 \mathrm{~N} \mathrm{HCl}, \mathrm{H}_{2} \mathrm{O}$, and buffer by applying a pressure of $20 \mathrm{psi}$ for 2, 1, 5, and $20 \mathrm{~min}$, respectively. The capillary was washed with buffer for 5 min between runs. The sample plug was introduced by applying a pressure of 0.5 psi for $5 \mathrm{~s}$ following which the ends of the capillary were dipped in water to avoid sample carry-over. Short-end injection was used unless otherwise specified. The separation was performed at $15 \mathrm{kV}$, and components were detected at $214 \mathrm{~nm}$. Thirty-two Karat ${ }^{\mathrm{TM}}$ analysis software (Beckman Coulter) was used to calculate retention times, peak widths, corrected peak areas, and resolution.

\section{Results and Discussion}

The CZE experiments presented in this paper were performed by using sodium phosphate buffer due to its low absorbance at the detection wavelength, i.e., $214 \mathrm{~nm}$. In addition, a broad and degraded peak of BG was observed at $\mathrm{pH} 8.5$, which suggested that the enzyme is unstable at high buffer $\mathrm{pH}$ values (Fig. 1). Therefore, buffers with a $\mathrm{pH}$ up to 8.0 were studied.

Experiments were also performed to obtain an Ohm's law plot for various concentrations of phosphate buffer at $\mathrm{pH}$ 7.5. A linear relationship between current and voltage was observed up to $25 \mathrm{mM}$ phosphate buffer concentration $[I=1.29-0.47 \mathrm{~V}$ (I, current and V, voltage), $\left.R^{2}=0.99\right]$. This suggests that capillary temperature was not adequately maintained at higher concentrations of the buffer. Therefore, considering the heat dissipating capacity of the P/ACETM MDQ CZE-system, the investigation into the effect of buffer $\mathrm{pH}$ was conducted using $25 \mathrm{mM}$ phosphate buffer at $15 \mathrm{kV}$.

\section{Effect of Buffer $\mathrm{pH}$ on the Separation of Enzymes}

The effect of $\mathrm{pH}$ on the separation of $\mathrm{CBH}, \mathrm{EG}$, and $\mathrm{BG}$ in sugarcane juice is presented in Fig. 2. The identities of the peaks were assigned by spiking. BG was found to exhibit the

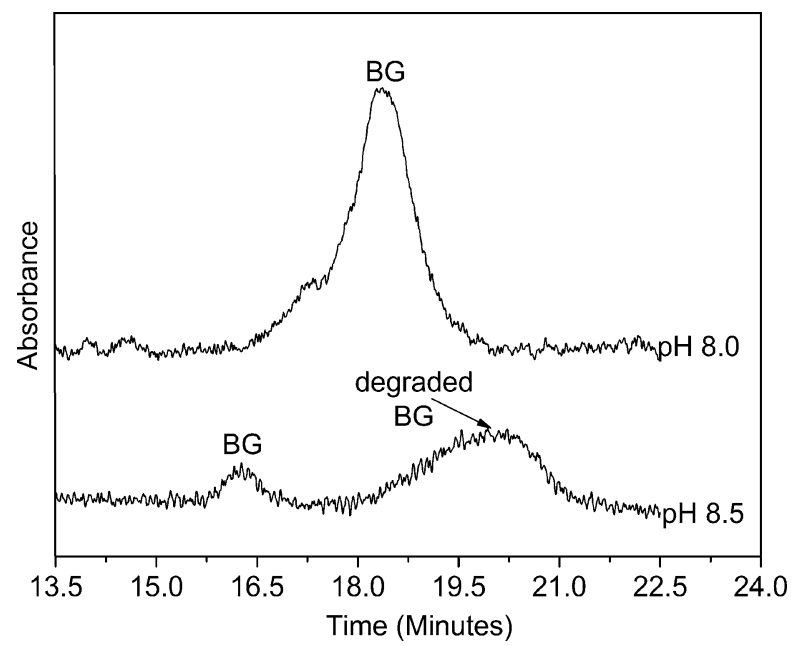

Fig. 1 Comparison of electropherograms of $\mathrm{BG}$ at $\mathrm{pH} 8.0$ and 8.5 (50 mM phosphate buffer, long-end injection) 


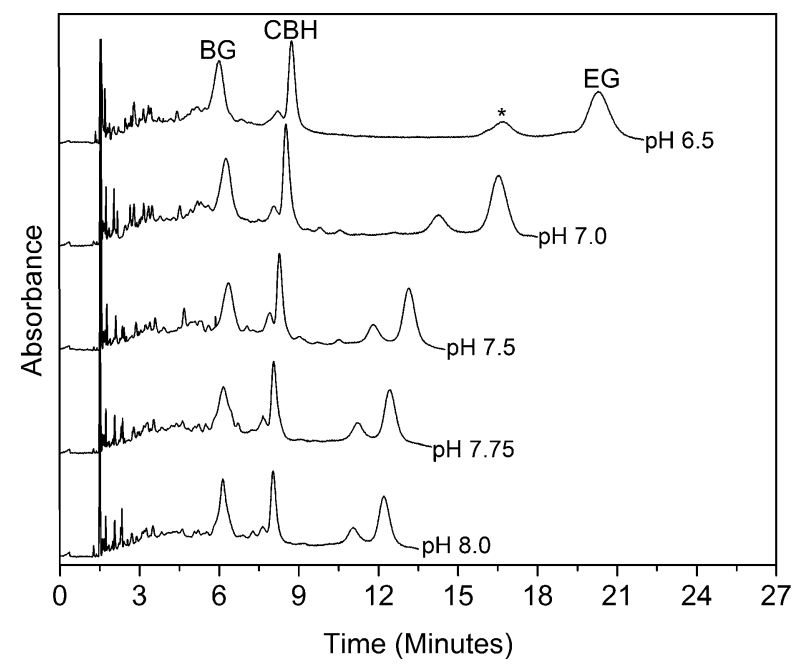

Fig. 2 Effect of $\mathrm{pH}$ on CZE separation of enzymes in sugarcane juice (25 mM phosphate buffer; single asterisk indicates unknown contaminant in EG)

highest mobility despite its greatest molecular weight which suggests that it is heavily charged. In addition, though the mobility of $\mathrm{EG}$ was increased at higher $\mathrm{pH}$, no appreciable change in the mobility of $\mathrm{BG}$ and $\mathrm{CBH}$ was observed between $\mathrm{pH} 6.5$ and 8.0. But $\mathrm{BG}$ and $\mathrm{CBH}$ possess a number of amino acid residues [28] with $\alpha-\mathrm{NH}_{2}$ terminal group (pKa, 6.4 or 6.68) and a few histidine ( $\mathrm{pKa}, 7.6$ or 8) residues [30]. Therefore, BG and $\mathrm{CBH}$ possess ionizable groups over the $\mathrm{pH}$ range used and it is likely that the two enzymes are fully ionized.

It is also clear from Fig. 2 that as the $\mathrm{pH}$ increases from 6.5 to 8.0 , the analysis time decreases from 22 to $13 \mathrm{~min}$. In addition, as the elution time of EG decreases, the time available for the diffusional broadening reduces. This results in increasing sharpness of the peaks. The effect was most notable on the peak width of EG which was reduced from 1.94 to $1.09 \mathrm{~min}$. But as the time scale contracts, shoulders begin to develop before and after the $\mathrm{BG}$ peak at $\mathrm{pH} 7.75$ and $\mathrm{pH} 8.0$ suggesting that $\mathrm{BG}$ is not fully separated from interfering components in the juice. In other words, the resolution of separation is hampered at these $\mathrm{pH}$ values. Considering the above-mentioned trade-offs, the use of phosphate buffer at $\mathrm{pH} 7.5$ was determined to be the most suitable.

Following this, multiple runs were performed at $\mathrm{pH} 7.5$ to check if the migration times of $\mathrm{BG}, \mathrm{CBH}$, and EG are reproducible. The results are shown in Fig. 3. The model presented in [31] predicted that variation in EOF is the major cause of these shifts. As the number of runs increased, there was a buildup of a layer of unidentified residues from the sugarcane juice on the inside walls of the capillary, resulting in increased EOF, and hence, an increase in migration times and peak widths. The relative standard deviations (RSD, $n=3$ ) of the migration times of $\mathrm{BG}, \mathrm{CBH}$, and $\mathrm{EG}$ were $1.8 \%, 2.4 \%$, and $6.6 \%$, respectively. Though it is possible to use this method for the routine analysis of $\mathrm{BG}, \mathrm{CBH}$, and $\mathrm{EG}$, the enzymes were purified from the juice to reduce the RSD of their migration times to enable automatic peak identification to be used.

The RSD ( $n=3$ ) of migration times of BG, CBH, and EG were found to be $0.84 \%$, $0.64 \%$, and $0.79 \%$, respectively, after sample preparation (electropherograms not shown) which is in comparison to which has been reported in the literature [32]. Therefore, 


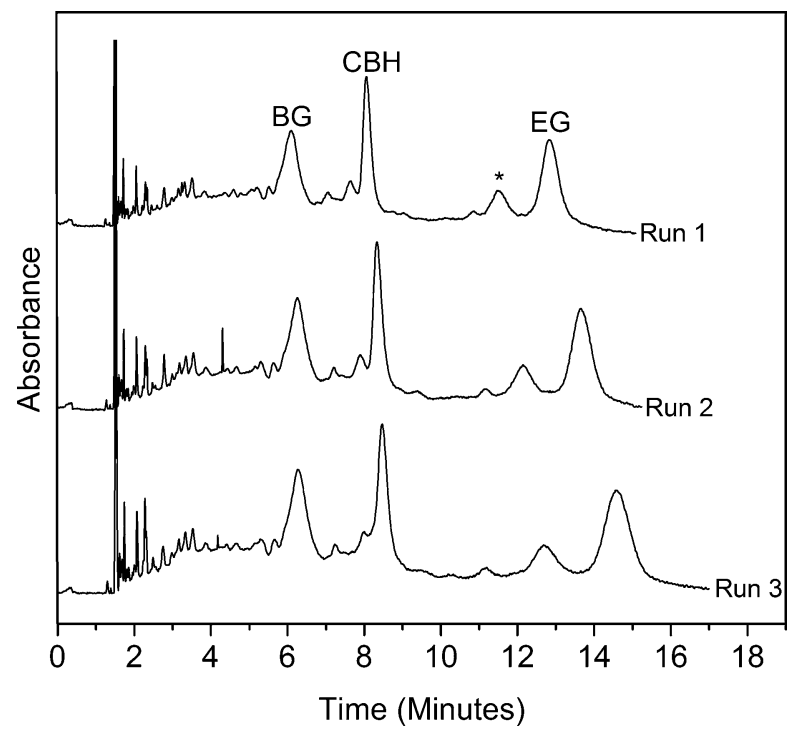

Fig. 3 Shift in migration time of BG, CBH, and EG due to sample matrix effects (phosphate buffer, pH 7.5, $25 \mathrm{mM}$; single asterisk indicates unknown contaminant in EG; Run 1 to Run 3 are sequential with 5 min intermediate wash)

coupling of the developed sample preparation method with the CZE method ensures peak identification using software. This in turn reduces the requirement of having trained analysts for interpretation of the results, thereby making it more suitable for at-line analysis in a process environment. Furthermore, purification of proteins from sugarcane juice allowed an increase of the buffer $\mathrm{pH}$ to 7.75 , thereby reducing the analysis time further, without degrading the resolution of separation (Fig. 4).

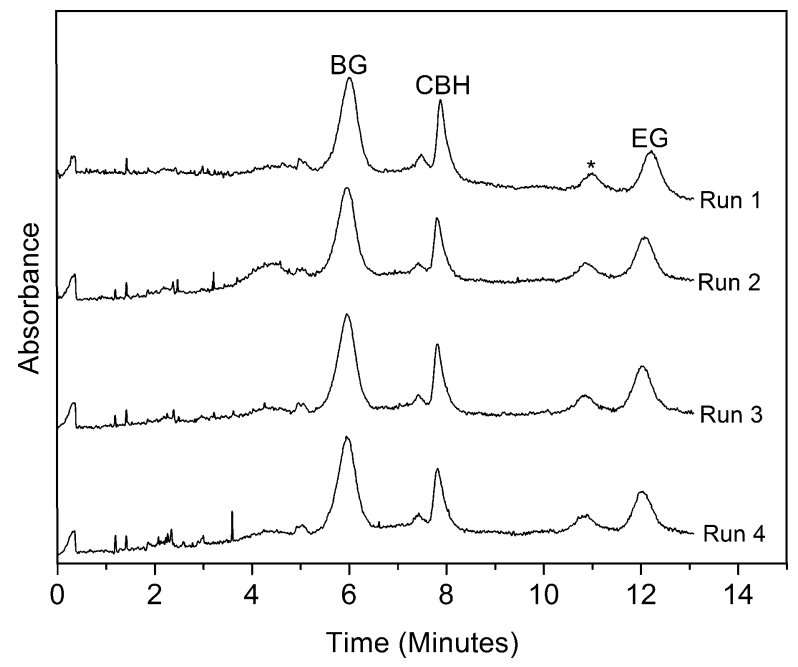

Fig. 4 Electropherograms of purified enzymes (phosphate buffer: pH 7.75, $25 \mathrm{mM}$; sample preparation: Vivaspin $^{\mathrm{TM}} 500,30 \mathrm{kDa}$ MWCO, PES membrane; single asterisk indicates unknown contaminant in EG; Run 1 to Run 4 are sequential with 5 min intermediate wash) 
Effect of Concentration of Buffer on the Separation of Enzymes

Figure 5 illustrates an exponential dependence of enzyme mobilities on the concentration of phosphate buffer. This effect is observed due to an exponential increase in the effective mobility with respect to square root of ionic strength [33]. The greater rate of increase in the mobility of BG with respect to buffer concentration further verifies that BG possesses a greater number of charged groups than $\mathrm{CBH}$ and EG [33].

Therefore, an important factor in favor of the use of a lower concentration of buffer is a decrease in separation time (Fig. 6). But in a $10 \mathrm{mM}$ phosphate buffer, BG and BSA are not baseline separated. Therefore, sodium phosphate buffer of $15 \mathrm{mM}$ and $\mathrm{pH} 7.75$ was found to be optimum for the separation of $\mathrm{CBH}, \mathrm{EG}$, and BG. Under these optimized conditions, the analysis was completed within 10 min. Hence, the CZE method reported in this paper is suitable for at-line analysis of $\mathrm{BG}, \mathrm{CBH}$, and $\mathrm{EG}$ in every batch of harvested sugarcane.

\section{Quantification of Enzymes}

It is necessary to know the initial concentration of standard enzyme solutions to obtain calibration curves and the limit of detection (LOD). The results on the concentrations of desalted cellulosic enzymes are summarized in Table 1.

In order to decide if the results obtained by using the two methods are significantly different, statistical $t$ and degree of freedom values for CBH, EG, and MIX were calculated. It is clear from Table 1 that the null hypothesis is retained for $\mathrm{CBH}$ and $\mathrm{EG}$, i.e., it has not been demonstrated that the concentration of these enzymes using RC-DCTM protein assay and NanoDrop ${ }^{\mathrm{TM}} 2000$ are different. However, the experimental $t$ value for MIX is greater than the critical value of 2.31. Therefore, the estimated concentrations of MIX using the two methods are significantly different. A probable cause for the observed discrepancy in the concentration of MIX could be the widely different absorption characteristics of BG and BSA making it difficult to estimate the net absorption coefficient of their mixture. The concentration of BG was estimated to be $0.7 \mathrm{mg} / \mathrm{ml}$ in the MIX of concentration $1.7 \mathrm{mg} / \mathrm{ml}$ based on the concentration ratio of BG and BSA in ammonium sulfate suspensions. To

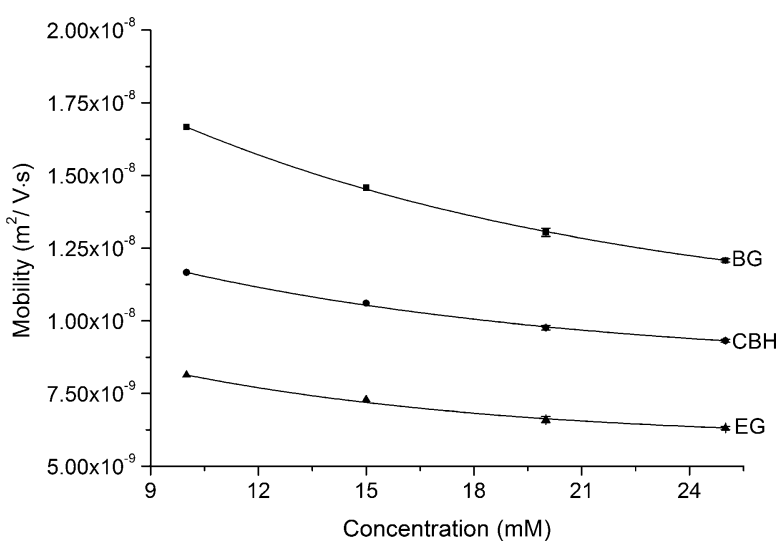

Fig. 5 Effect of phosphate buffer concentration on enzyme mobility ( $n=3$, error bars indicate \pm standard deviation and RSD is below $1.65 \%$ ) 


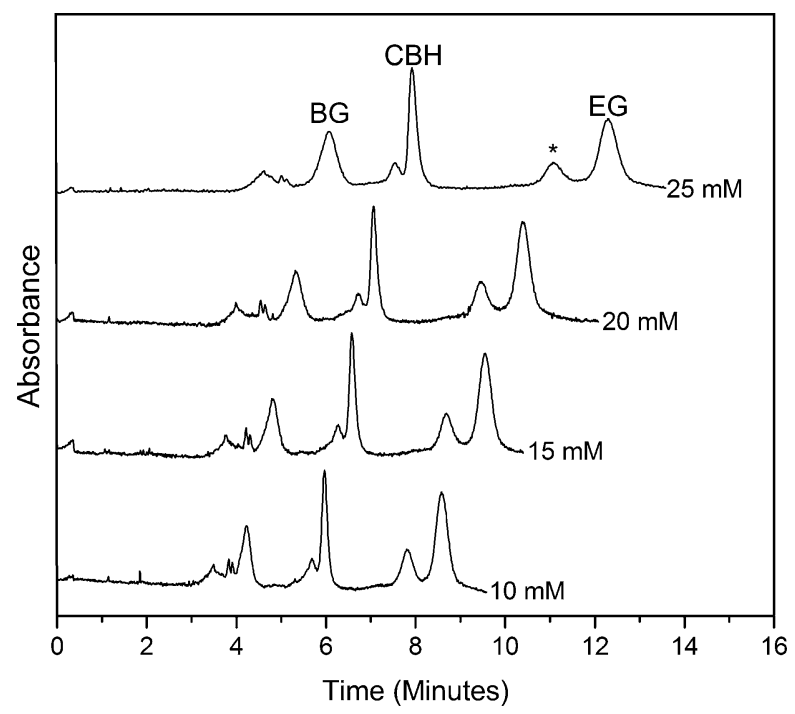

Fig. 6 Effect of buffer concentration on separation of $\mathrm{CBH}, \mathrm{EG}$, and $\mathrm{BG}$ (pH 7.75; single asterisk indicates unknown contaminant in EG)

summarize, the starting concentration of reference solutions of $\mathrm{CBH}, \mathrm{EG}$, and BG were 8.1, 10.41 , and $0.7 \mathrm{mg} / \mathrm{ml}$, respectively.

The linearity of the method was tested in the range of 20 to 250,20 to 100 , and 20 to $150 \mathrm{mg} / \mathrm{L}$ for $\mathrm{CBH}, \mathrm{EG}$, and $\mathrm{BG}$, respectively. The enzyme standards at different concentrations were ran as triplicates, and the results are summarized in Table 2.

The RSDs of the migration times of cellulosic enzymes were between $0.56 \%$ and $0.7 \%$. The calibration curves for the enzymes were plotted using corrected peak area to account for variations in migration time [34] and resulted in regression coefficients $\left(R^{2}\right)$ above 0.99 . The RSD of the peak areas between the three replicates was on average $5.3 \pm 3.3 \%$ for samples with enzyme concentration above $20 \mathrm{mg} / \mathrm{l}$. This is comparable to the results obtained by Jørgensen et al. using their CZE method for quantification of cellulases from $P$. brasilianum Batista IBT 20888 [24]. The LODs for enzymes were estimated by using the blank signal $\left(y_{\mathrm{B}}\right)$ plus three times the standard deviation associated with this value [35]. But the negative values of $y_{\mathrm{B}}$ do not have a physical meaning. Since $y_{\mathrm{B}}=0$ corresponds to the minimum concentration of the enzyme required to obtain a measurable absorbance signal, $y_{\mathrm{B}}$ was assumed to be zero to calculate the LODs of the enzymes. Using this definition, the LODs for CBH, EG, and BG are 6.4, 40.35, and $4.25 \mathrm{mg} / \mathrm{l}$, respectively. The broader peak of EG compared to the other two enzymes could be a probable cause of the higher LOD of $\mathrm{EG}$, though the exact cause of the problem is not known for certain. It should also be noted

Table 1 Concentrations of desalted enzymes using two methods and parameters for statistical tests (based on definitions in [34])

\begin{tabular}{|c|c|c|c|c|c|}
\hline Enzyme & $\mathrm{RC}-\mathrm{DC}^{\mathrm{TM}}(n=9)$ & NanoDrop $^{\mathrm{TM}} 2000(n=9)$ & $\left|t_{\exp }\right|$ & Degrees of freedom & $\left|t_{\text {crit }}\right|(P=0.05)$ \\
\hline $\mathrm{CBH}$ & $8.1 \pm 0.65$ & $8.82 \pm 1.64$ & 1.224 & 10 & 2.23 \\
\hline EG & $10.48 \pm 0.95$ & $10.41 \pm 0.34$ & 0.208 & 10 & 2.23 \\
\hline $\mathrm{MIX}=\mathrm{BG}+\mathrm{BSA}$ & $1.7 \pm 0.45$ & $1.16 \pm 0.034$ & 3.589 & 8 & 2.31 \\
\hline
\end{tabular}


Table 2 LOD, linearity, and RSD of migration times of CBH, EG, and BG

\begin{tabular}{lccccc} 
Enzyme & Regression line & $R^{2}$ & LOD $(\mathrm{mg} / \mathrm{l})$ & Average migration time (min) & \% RSD of migration time \\
\hline CBH & $0.015 \times-0.048$ & 0.999 & 6.4 & 6.68 & $0.56(n=27)$ \\
EG & $0.017 \times-0.212$ & 0.998 & 40.35 & 9.65 & $0.7(n=15)$ \\
BG & $0.046 \times-0.154$ & 0.998 & 4.25 & 3.69 & $0.7(n=15)$ \\
\hline
\end{tabular}

that the developed method is actually capable of detecting lower concentrations of $\mathrm{CBH}$, $\mathrm{EG}$, and BG than their stated LODs because the LOD has been overestimated due to the assumption that $y_{\mathrm{B}}=0$.

Transgenic rice has been reported to accumulate EG to levels of $\sim 5 \%$ of total soluble proteins [36]. In addition, sugarcane juice contains $\sim 1,000 \mathrm{mg} / \mathrm{L}$ of soluble proteins [37]. The commercially available enzyme products used for efficient hydrolysis of biomass consists of approximately $75-80 \%$ of $\mathrm{CBH}, 20 \%$ of EG, and $2-5 \%$ of BG [3]. Therefore, the concentration of $\mathrm{CBH}, \mathrm{EG}$, and BG expressed in sugarcane is expected to be 190-200, 50 , and 5-13 mg/l, respectively. To summarize, the developed method is suitable to monitor the expected concentration of enzymes in GM sugarcane plants.

\section{Sample Preparation-Ultrafiltration and Extraction Efficiency}

In the past 10 years, ultrafiltration (UF) has emerged as a promising alternative to conventional sugarcane juice clarification [38]. As a result, most mill operators are highly likely to have experience in using UF. This makes UF an attractive sample preparation technique for at-line monitoring of the concentration of cellulases in sugarcane juice. Besides sugars (such as glucose, fructose, and sucrose) and salts, cane juice contains soluble solids in the form of coloring pigments (such as anthocyanin and chlorophyll), polysaccharides, proteins, and so on [37]. These high molecular mass species are not removed due to UF. But the RSD in migration times of enzymes was reduced after sample preparation. Hence, it is likely that sugars and salts were affecting the EOF by changing the surface characteristics of the CZE capillary and ionic strength, respectively. But injecting a plug of sugarcane juice into the CZE capillary did not have any effect on the observed current. This suggests that the presence of sugars in the juice is the likely cause of variations in migration time of $\mathrm{CBH}, \mathrm{EG}$, and $\mathrm{BG}$. In comparison to coloring pigments, polysaccharides, and proteins, the variations in the amount of sugars and salts in sugarcane juice are much higher due to differences in cane variety and age as well as due to external factors (e.g., soil type, fertilizers, climate, and water) [39]. Therefore, the use of UF for

Table 3 Percentage extraction efficiency of the enzymes using different MWCO PES membranes $(n=3)$

\begin{tabular}{lllll}
\hline Enzyme & \multicolumn{5}{l}{ PES } & & \\
\cline { 2 - 3 } & $10 \mathrm{kDa}$ & & $30 \mathrm{kDa}$ & \\
\cline { 2 - 3 } \cline { 5 - 5 } & $\begin{array}{l}\text { Concentration } \\
(\mathrm{mg} / \mathrm{ml})\end{array}$ & Extraction efficiency $(\%)$ & $\begin{array}{l}\text { Concentration } \\
(\mathrm{mg} / \mathrm{ml})\end{array}$ & Extraction efficiency $(\%)$ \\
\hline $\mathrm{CBH}$ & $61.4 \pm 4.49$ & $75.8 \pm 5.5$ & $46.69 \pm 11.38$ & $57.76 \pm 14.05$ \\
$\mathrm{EG}$ & $56.33 \pm 3.56$ & $56.33 \pm 3.56$ & $39.42 \pm 7.07$ & $39.42 \pm 7.07$ \\
$\mathrm{BG}$ & $19.46 \pm 0.64$ & $79.43 \pm 2.61$ & $19.13 \pm 4.15$ & $78.08 \pm 16.9$ \\
\hline
\end{tabular}


cellulosic enzymes preparation eliminates variable matrix effects on their CZE-based separation and quantification.

Using the information on the volume of enzymes added to sugarcane juice and the initial concentration of standard cellulase solutions, the concentration of $\mathrm{CBH}, \mathrm{EG}$, and BG in cane juice was estimated to be 81,100 , and $24.5 \mathrm{mg} / \mathrm{ml}$, respectively, before sample preparation. A comparison of their concentration and percentage extraction efficiency by using PES membranes of different MWCO is presented in Table 3.

From Table 3, it is clear that a PES membrane with a MWCO of $10 \mathrm{kDa}$ resulted in maximum extraction efficiency of enzymes from the juice. It should be noted that regenerated cellulose-based membranes are unsuitable for the purpose because the desired enzymes degrade cellulose. Therefore, the use of a $10 \mathrm{kDa}$ PES membrane is recommended for the purification of $\mathrm{CBH}, \mathrm{EG}$, and $\mathrm{BG}$ in sugarcane juice.

\section{Conclusions}

The effect of $\mathrm{pH}$ and concentration of the buffer on the CZE-based separation of CBH, EG, and BG was studied. The optimized method offers adequate dynamic range and limits of detection to measure the concentration of cellulases in GM sugarcane. The use of $10 \mathrm{kDa}$ MWCO, PES membrane improved the robustness of the method by increasing the reproducibility of the migration times making it suitable for use in an automated analysis environment. While this study used centrifugal/gravitational force as the driving force behind the removal of undesirable particles through the membrane, the method is equally applicable with the use of other forces such as electrical, hydraulic, electromagentic, and so on. Thus the sample preparation method reported in this paper could be further developed for online sampling, thereby alleviating the requirements of manual removal of the sample.

Acknowledgments This research was funded by Syngenta and the University of Manchester. The authors would also like to thank Dr. Jeff E. Prest for the helpful discussions.

\section{References}

1. Balat, M., Balat, H., \& Oz, C. (2008). Progress in Energy and Combustion Science, 34, 551-573.

2. Halling, P., \& Simms-Borre, P. (2008). International Sugar Journal, 110, 191-194.

3. Merino, S. T., \& Cherry, J. (2007). Advances in Biochemical Engineering/Biotechnology, 108, 95-120.

4. Hopes for Mackay to House Ethanol Plant. Available from: www.abc.net.au/news/stories/2008/05/27/ 2256492.htm. Accessed March 31 22, 2010.

5. Official Energy Statistics from the U.S. Government (Australia-Quick Facts), www.eia.doe.gov/emeu/ cabs/Australia/Profile.html. Accessed March 31 22, 2010.

6. Biswas, G. C. G., Ransom, C., \& Sticklen, M. (2006). Plant Science, 171, 617-623.

7. Jepson, I., Martinez, A., \& Sweetman, J. P. (1998). Pesticide Science, 54, 360-367.

8. Rudnitskaya, I., \& Legin, A. (2008). Journal of Industrial Microbiology \& Biotechnology, 35, 443-451.

9. Kumar, P., \& Wyman, C. E. (2008). Enzyme and Microbial Technology, 42, 426-433.

10. Hendel, B., \& Marxsen, J. (2005). Methods to study litter decomposition: A practical guide. Netherland: Springer.

11. Philpott, W. A., \& Chapman, J. A. (1977). Analytical Biochemistry, 79, 257-262.

12. Deshpande, M. V., Eriksson, K. E., \& Pettersson, L. G. (1984). Analytical Biochemistry, 138, 481-487.

13. Sharrock, K. R. (1988). Journal of Biochemical and Biophysical Methods, 17, 81-106.

14. Twyman, R. M. (2004). Principles of proteomics. Oxfordshire, UK: BIOS Scientific.

15. Landers, J. P. (2008). Handbook of capillary and microchip electrophoresis and associated microtechniques (3rd ed.). Florida, USA: CRC press. 
16. Ellouz, S., Durand, H., \& Tiraby, G. (1987). Journal of Chromatography, 396, 307-317.

17. Medve, J., Lee, D., \& Tjerneld, F. (1998). Journal of Chromatography A, 808, 153-165.

18. Jørgensen, H., Eriksson, T., Borjesson, J., Tjerneld, F., \& Olsson, L. (2003). Enzyme and Microbial Technology, 32, 851-861.

19. Shihabi, Z. K. (2004). Journal of Chromatography. A, 1027, 179-184.

20. Hood, E. E., Love, R., Lane, J., Bray, J., Clough, R., Pappu, K., et al. (2007). Plant Biotechnology Journal, 5, 709-719.

21. Mach, R. L., \& Zeilinger, S. (2003). Applied Microbiology and Biotechnology, 60, 515-522.

22. de Vries, R. P., \& Visser, J. (2001). Microbiology and Molecular Biology Reviews, 65, 497-522.

23. Khaled, M. Y., McNair, H., Polite, L., \& Pauls, R. (1995). Journal of Microcolumn Separations, 7, $429-$ 433.

24. Jørgensen, H., Kutter, J. P., \& Olsson, L. (2003). Analytical Biochemistry, 317, 85-93.

25. Jørgensen, H., \& Olsson, L. (2006). Enzyme and Microbial Technology, 38, 381-390.

26. Jørgensen, H., Mørkeberg, A., Krogh, K. B. R., \& Olsson, L. (2005). Enzyme and Microbial Technology, $36,42-48$.

27. Ståhlberg, J., Johansson, G., \& Pettersson, G. (1993). Biochimica et Biophysica Acta, 1157, 107-113.

28. Universal Protein Resource. Available from: www.uniprot.org/. Accessed March 31, 2010.

29. Hui, J. P. M., White, T. C., \& Thibault, P. (2002). Glycobiology, 12, 837-849.

30. Henriksson, G., Englund, A., Johansson, G., \& Lundahl, P. (1995). Electrophoresis, 16, 1377-1380.

31. Reijenga, J. C., Martens, J. H. P. A., Giuliani, A., \& Chira, M. (2002). Journal of Chromatograhy B, $770,45-51$.

32. Dabek-Zlotorzynska, E., Aranda-Rodriguez, R., \& Keppel-Jones, K. (2001). Electrophoresis, 22, 4262 4280.

33. Friedl, W., Reijenga, J. C., \& Kenndler, E. (1995). Journal of Chromatography A, 709, 163-170.

34. Heck, J. M. L., Olieman, C., Schennink, A., van Valenberg, H. J. F., Visker, M. H. P. W., Meuldijk, R. C. R., et al. (2008). International Dairy Journal, 18, 548-555.

35. Miller, J. N., \& Miller, J. C. (2005). Statistics and chemometrics for analytical chemistry (5th ed.). Pearson Prentice Hall, Essex, UK: Harlow.

36. Sticklen, M. B. (2008). Nature Reviews. Genetics, 9, 433-443.

37. Chen, J. C. P., \& Chou, C. C. (1993). Cane sugar handbook: A manual for cane sugar manufacturers and their chemists (12th ed.). New York, USA: Wiley.

38. Kishihara, S., Tamaki, H., Wakiuchi, N., \& Fujii, S. (1993). International Sugar Journal, 1135, 273-277.

39. van Dillewijn, C. (1952). Botany of sugarcane (1st ed.). Massachusetts, USA: The Chronica Botanica Co. 